\title{
Pubic Symphysis
}

National Cancer Institute

\section{Source}

National Cancer Institute. Pubic Symphysis. NCI Thesaurus. Code C33425.

The joint between the left and right pubic bones at the front of the pelvis. 